\title{
Empreendimentos de Economia Solidária: Território Oeste Catarinense
}

\author{
Entrepreneurship of Solidary Economy: Western Territory of Santa Catarina
}

Les entreprises de l'Économie Solidaire: Territoire Ouest de Santa Catarina

Emprendimientos de Economía Solidaria: Territorio Oeste Catarinense

\author{
Andreia Casagrande ${ }^{1}$ \\ Sérgio Begnini ${ }^{2}$ \\ Recebido em 08/01/2017; revisado e aprovado em 11/07/2017; aceito em 04/08/2017 \\ DOI: http://dx.doi.org/10.20435/inter.v19i1.1467
}

Resumo: Este estudo tem por objetivo apresentar os principais dados dos Empreendimentos de Economia Solidária (EES) existentes no Território Oeste Catarinense (TOC). Metodologicamente, classifica-se como quantitativo, exploratório e descritivo. Os dados coletados para este artigo são secundários, retirados do segundo mapeamento realizado pela Secretaria Nacional de Economia Solidária (SENAES). Os resultados indicam que os EES atuam, em sua maioria, na área rural, tendo como principal atividade econômica a produção e comercialização de seus produtos e, entre as motivações para atuar nos empreendimentos, a possibilidade de aumentar ou complementar a renda familiar. Dos sócios e sócias, 64\% são agricultores familiares e comercializam os produtos oriundos da agricultura.

Palavras-chave: empreendimentos; economia solidária; território.

Abstract: The purpose of this study is to present the main data of the Solidarity Economy Enterprises (EES) existing in the Western Territory of Santa Catarina (TOC). Methodologically, it is classified as quantitative, exploratory and descriptive. The data collected for this article are secondary to the second mapping carried out by the National Secretariat for Solidarity Economy (SENAES). The results indicate that the SEES work mainly in the rural area, having as main economic activity the production and marketing of their products and among the motivations to act in the ventures the possibility of increasing or complementing the family income. Of the partners and members $64 \%$ are family farmers and market the products from agriculture.

Keywords: entrepreneurship; solidarity economy; territory.

Résumé: Cet étud vise à présenter les principales données de l'économie solidaire Entreprises (ESS) existant dans le Territoire Ouest de Santa Catarina (TOC). Méthodologiquement est classé en tant que quantitative, descriptive et exploratoire. Les données recueillies pour cet article sont extraites de la seconde cartographie latérale réalisée par le Secrétariat national de l'économie solidaire (SENAES). Les résultats indiquent que les EES opèrent principalement dans les zones rurales, la principale activité économique est la production et la commercialisation de ses produits et parmi les motivations pour travailler dans les entreprises la possibilité d'augmenter ou de compléter le revenu familial. Des membres et des partenaires $64 \%$ sont des agriculteurs et la commercialisation de produits issus de l'agriculture.

Mots-clés: l'esprit d'entreprise; l'économie solidaire; territoire.

Resumen: Este estudio tiene como objetivo presentar los principales datos de los emprendimientos de economía solidaria (EES) existentes en el Territorio Oeste Catarinense (TOC). Metodológicamente, se clasifica como cuantitativo, exploratorio y descriptivo. Los datos recogidos para este artículo son secundarios retirados del segundo mapeo realizado por la Secretaría Nacional de Economía Solidaria (SENAES). Los resultados indican que los EES actúan en su mayoría en el área rural, teniendo como principal actividad económica la producción y comercialización de sus productos y entre las motivaciones para actuar en los emprendimientos la posibilidad de aumentar o complementar la renta familiar. De los socios y socias el $64 \%$ son agricultores familiares y comercializan los productos oriundos de la agricultura.

Palabras clave: emprendimientos; economía solidaria; territorio.

\footnotetext{
${ }^{1}$ Faculdade Senac, Chapecó, Santa Catarina, Brasil.

${ }^{2}$ Universidade Federal da Fronteira Sul (UFFS), Chapecó, Santa Catarina, Brasil.
} 


\section{INTRODUÇÃO}

Na busca pelo desenvolvimento, diversos gestores públicos deram ênfase ao crescimento econômico e à inserção no mercado mundial, deixando de considerar igualmente todas as dimensões (social, econômica, demográfica, ambiental) que perfazem o desenvolvimento sustentável. Esse processo de olhar fragmentado contribui para o aumento das desigualdades sociais e afasta os cidadãos das decisões e do planejamento da sociedade. A ausência da participação social implementa o modelo de políticas planejadas e executadas de "cima para baixo". Entende-se que tal realidade pode ser alterada à medida que as pessoas sentem a necessidade de atuar como agentes no desenvolvimento do território em que vivem.

A palavra "desenvolvimento" tem assumido diferentes definições conforme o momento histórico e o setor de aplicação, sendo utilizada pelas ciências sociais, políticas e econômicas. Em algumas épocas, era entendida como sinônimo de "crescimento", "aumento de riqueza" e "produtividade".

O termo "desenvolvimento" começou a ser mais utilizado no fim da Segunda Guerra Mundial, nos Estados Unidos, com uma grande campanha política em âmbito global denominada "A Era do Desenvolvimento". O então presidente Truman usou pela primeira vez a palavra "subdesenvolvido". A partir daquele momento, os países buscaram constantemente fugir dessa condição e aproximar-se da realidade considerada "ideal", a norte-americana (ESTEVA, 2000).

Na década de 1970, destacaram-se propostas geridas de "baixo para cima", ou seja, discutidas pela sociedade, suscitando assim uma corrente de pensamento sobre a problemática dos desequilíbrios regionais, originando o termo "desenvolvimento endógeno". A principal contribuição das teorias endogenistas foi identificar como as instituições e os fatores ligados à produção afetavam o desenvolvimento e como o potencial de uma região poderia ser gerenciado por ela mesma (MORAES, 2003). Portanto o desenvolvimento endógeno pode ser considerado uma base para a execução de políticas públicas que fortaleçam as estruturas internas e criem condições sociais e econômicas para a atração de novas alternativas produtivas para o território (AMARAL FILHO, 2001).

O conceito de "desenvolvimento territorial" refere-se aos processos de descentralização das últimas décadas que valorizam os elementos endógenos. É possível definir "desenvolvimento territorial" como "[...] o plano de ação coordenado, descentralizado e focalizado destinado a ativar e melhorar as condições de vida dos habitantes de uma localidade, que estimula a participação dos atores" (COELHO, 1997, p. 48).

Nesse sentido, a abordagem territorial transpõe as divisões físicas. É um conceito abrangente e em construção, contemplando relações econômicas, sociais, políticas, culturais, entre outras. Caccia Bava (1994) descreve algumas experiências de comercialização de produtos nos pequenos e médios municípios que têm auxiliado no desenvolvimento das potencialidades econômicas e gerado renda para a população. Entre elas, menciona o artesanato, as cooperativas, as associações ou redes.

O desenvolvimento territorial favorece o surgimento de espaços participativos e um conhecimento da realidade local, permitindo o estreitamento das relações sociais, a cooperação e a valorização (AMARAL FILHO, 2001). As ações desenvolvidas de forma endógena auxiliam no fomento da aprendizagem, do conhecimento e da informação, promovendo qualificação profissional e pessoal. Nesse sentido, a Economia Solidária é uma forma de participação social e desenvolvimento do território, uma vez que organiza práticas econômicas e solidárias pautadas 
pelo trabalho associativo e autogestionário, com propriedade coletiva, respeito às diversidades e ao meio ambiente.

Considerando que a Economia Solidária se apresenta como uma alternativa para o fortalecimento do desenvolvimento territorial, este estudo tem o objetivo de apresentar os principais dados dos Empreendimentos de Economia Solidária (EES) existentes no Território Oeste Catarinense (TOC). O artigo está estruturado em cinco partes: a presente introdução, a seção que trata da Economia Solidária no Brasil, a metodologia, a apresentação dos resultados, e as considerações finais.

\section{A ECONOMIA SOLIDÁRIA NO BRASIL}

Ao longo do século XVIII, após a Revolução Industrial, práticas econômicas começaram a ser pensadas em diversos países uma vez que o modelo capitalista apresentava fragilidades com relação ao modo de trabalho. O desemprego levou ao aumento da informalidade em um contexto no qual os trabalhadores chegavam a abrir mão de seus direitos para garantir a sobrevivência (BENINI et al., 2012).

Para superar os obstáculos que surgiram com o capitalismo industrial, os trabalhadores começaram a se organizar na forma de cooperativismo, criando sindicatos, associações, num movimento que impulsionou os trabalhadores a assumirem as empresas falidas buscando garantir a geração de renda (BENINI et al., 2012). A crise, ao mesmo tempo que se apresentava como fator de preocupação, servia como estímulo e incentivo aos atores sociais que buscaram novos espaços e alternativas para geração de renda e sobrevivência. A ativação das fábricas deu-se de forma cooperativa autogestionária (BENINI et al., 2012).

No Brasil, as iniciativas relacionadas ao cooperativismo iniciaram no século XX. Ao longo da década de 1990, surgiu o movimento de Economia Solidária no País, em resposta ao desemprego estrutural (FAVARIN, 2010). No ano de 1996, Paul Singer utilizou de modo pioneiro aqui a expressão "Economia Solidária", prática que foi sendo articulada com diversos atores: organizações sindicais, ONGs, estudantes, universidades, religiosos, gestores públicos, entre outros.

Para Singer (2003), a Economia Solidária no Brasil é resultante dos movimentos sociais e trabalhadores atingidos pela crise do desemprego que iniciou em 1981 e se agravou em 1990, com a abertura do mercado interno para as importações. Nesse sentido, é considerada uma nova forma de geração de trabalho, distribuição de renda e organizações geridas pelos trabalhadores.

Em janeiro de 2011, na cidade de Porto Alegre, ocorreu o I Fórum Social Mundial (I FSM), constituindo-se o Grupo de Trabalho Brasileiro de Economia Solidária (GT-Brasileiro). De acordo com os registros do Fórum Brasileiro de Economia Solidária (FBES, 2013), participaram do GT-Brasileiro alguns gestores públicos, entidades e redes nacionais: a Rede Brasileira de Socioeconomia Solidária (RBSES), a Associação Brasileira de Instituições de Microcrédito (ABCRED), o Instituto Políticas Alternativas para o Cone Sul (PACS), a Associação Nacional dos Trabalhadores de Empresas em Autogestão (ANTEAG), a Federação de Órgãos para a Assistência Social e Educacional (FASE), o Instituto Brasileiro de Análises Socioeconômicas (IBASE), a Cáritas Brasileira, o Movimento dos Trabalhadores Sem Terra (MST), a Rede Universitária de Incubadoras Tecnológicas de Cooperativas Populares (Rede ITCPs), a Agência de Desenvolvimento Solidário (ADS/CUT), entre outras (FBES, 2013).

A I Plenária Brasileira de Economia Solidária ocorreu em dezembro de 2002, no Estado de São Paulo, e teve como principal resultado uma carta ao então Presidente Luiz Inácio Lula da Silva 
pleiteando uma secretaria para a Economia Solidária. Em janeiro de 2003, em Porto Alegre, junto com o III Fórum Social Mundial, ocorreu a II Plenária Brasileira da Economia Solidária, definindo a agenda de mobilizações e debates e substituindo a denominação "GT-Brasileiro" por "Fórum Brasileiro de Economia Solidária" (FBES, 2013).

A Economia Solidária passou a fazer parte da agenda do Governo Federal e a ser incluída nas ações de políticas públicas a partir de 2003, sendo entendida como uma alternativa para a geração de trabalho e renda. A fim de atender esse público, o governo implantou a Secretaria Nacional de Economia Solidária (SENAES) e, vinculado ao Ministério do Trabalho, o Programa Economia Solidária em Desenvolvimento. Dias após a constituição da SENAES, ocorreu a III Plenária Nacional, em junho de 2003, momento em que a Economia Solidária começou a se consolidar como organização em redes, com 27 Fóruns Municipais/Regionais (BRASIL, 2012).

Com a criação da SENAES, uma das necessidades que surgiu foi a de obter informações sobre os empreendimentos existentes no País. Para tanto, foi realizado um trabalho de mapeamento, que teve início em 2003, finalizado em 2005. No ano de 2006, foi criado um banco de dados nacional, chamado Sistema Nacional de Informações de Economia Solidária (SIES), que possibilitou, em 2007, a ampliação de dados do mapeamento (BRASIL, 2012).

De 2007 a 2010, a Economia Solidária foi contemplada por diversos editais e chamadas públicas que possibilitaram, por meio de projetos, o desenvolvimento de ações com os empreendimentos. Em 2010, a SENAES passou a contar com pessoas de referência nas Delegacias Regionais do Trabalho - unidades descentralizadas do Ministério do Trabalho -, ganhando espaço e visibilidade (BRASIL, 2012).

No ano de 2013, foi finalizado o segundo mapeamento da Economia Solidária no Brasil, disponibilizado para acesso em 2014, apresentando aspectos relevantes para a análise da atuação dos Empreendimentos de Economia Solidária (EES) no País. O envolvimento e a participação de diferentes atores nos EES tendem a fortalecer as potencialidades locais, ou seja, o desenvolvimento endógeno.

No Brasil, o debate sobre o desenvolvimento endógeno tem considerado o território como unidade básica para a gestão das políticas públicas. Nesse contexto, entende-se por "território" o espaço que apresenta as dimensões política, cultural, econômica em um campo de relações. De acordo com Moraes (2003), o ambiente do território exige o desenvolvimento de instituições democráticas, modernas, representativas, transparentes e que possibilitam o planejamento com a participação da população. "É onde interagem as organizações comunitárias, as unidades empresariais, as redes de infraestrutura e os intermediários comerciais e financeiros. [...] Para isso, são necessários mecanismos diferenciados de gestão, que articulem os governos e as instituições locais com a sociedade" (MORAES, 2003, p. 6).

A Secretaria do Desenvolvimento Territorial (SDT) do Ministério do Desenvolvimento Agrário (MDA) planejou, como forma de aproximação dos municípios, a divisão destes em territórios geográficos, para que, com uma área menor, fosse possível alcançar as metas de redução das desigualdades sociais, superação da pobreza e promoção de um estilo de desenvolvimento rural sustentável (PLANO TERRITORIAL DE DESENVOLVIMENTO RURAL SUSTENTÁVEL [PTDRS], 2010).

Como estratégia para o alcance da meta, a SDT adotou a articulação entre diversas entidades de apoio que atuam nas diferentes organizações e segmentos sociais que envolvem os territórios, dentre essas a SENAES. No ano de 2003, quando criada a Secretaria de Desenvolvimento Territorial, a SENAES passou a integrar suas ações no Programa de Desenvolvimento Sustentável 
de Territórios Rurais (PRONAT), estabelecendo uma comunicação entre a Economia Solidária e a agricultura familiar (BRASIL, 2012). Em 2004, foi criada a linha de Elaboração do Plano Territorial de Desenvolvimento Rural Sustentável (PTDRS); em 2006, foi inaugurada a linha de apoio a gestão do PTDRS, a fim de qualificar as ações de planejamento dos territórios rurais (LEITE; WESZ JUNIOR, 2012). Para a agricultura familiar e os assentamentos da Reforma Agrária, em 2007, foi instituída a ação de fomento aos empreendimentos que fossem oriundos desses segmentos. Em 2008, foi criada uma linha de fortalecimento às iniciativas territoriais de conservação e manejo sustentável da agrobiodiversidade (LEITE; WESZ JUNIOR, 2012).

O trabalho com os territórios se manteve em 2010, com a execução do PTDRS, que visava promover o desenvolvimento com igualdade e inclusão, seguindo as diretrizes das políticas públicas do Governo Federal (PTDRS, 2010). Em 2013, a SENAES completou dez anos de funcionamento; contudo, devido à mudança no cenário político e econômico do País, os recursos destinados ao desenvolvimento de políticas públicas voltadas ao Plano Territorial de Desenvolvimento Rural Sustentável e à Economia Solidária foram sendo reduzidos. Em novembro de 2016, por estratégia do Governo Federal visando à redução de gastos públicos, a SENAES foi extinta, sendo criada uma subsecretaria de Economia Solidária dentro da Secretaria de Relações do Trabalho.

Considera-se que os EES estão em um momento de incertezas e inseguranças, uma vez que os editais e projetos que destinavam recursos para os EES, bem como para o desenvolvimento do território, foram reduzidos.

\section{METODOLOGIA}

O presente estudo possui abordagem quantitativa. Quanto aos fins, pode ser classificado como exploratório, pois permite ao pesquisador intensificar sua experiência em torno da problemática (TRIVIÑOS, 2009), e como descritivo, pois descreve características de determinado fenômeno ou população, estabelecendo relação entre as variáveis (GIL, 2002).

Quanto aos meios, a pesquisa pode ser classificada em bibliográfica e documental, considerando a literatura existente sobre o tema e os documentos formalizados e que estão à disposição para serem utilizados. Para Gil (2002), uma das principais características desse tipo de pesquisa é o fato de permitir ao pesquisador uma cobertura ampla dos inúmeros fatos e dados que não precisam ser pesquisados diretamente.

\section{1 Área de estudo}

A área de estudo é o Território Oeste Catarinense, sendo esse um recorte no Estado de Santa Catarina (SC). De acordo com dados do Instituto Brasileiro de Geografia e Estatística (IBGE, 2010), Santa Catarina possui uma população estimada de 6.634.254, em uma área de 95.736,165 $\mathrm{km}^{2}$ e 295 municípios. Comparativamente a outros estados brasileiros, pode-se dizer que Santa Catarina encontra-se em uma situação privilegiada por obter 1,12\% de todo o território nacional e possuir um processo de industrialização distribuído por todas as suas regiões, além de um dos maiores Índice de Desenvolvimento Humano (IDH) do Brasil: 0,774, faixa considerada alta (INSTITUTO DE PESQUISA ECONÔMICA APLICADA [IPEA], 2013).

A economia de Santa Catarina passou por transformações durante o século XX, e as atividades econômicas que eram predominantemente agrícolas passaram a dar espaço também às atividades industriais. A colonização das regiões do estado ocorreu por diferentes culturas e 
migrações, fator que possibilitou a vasta diversidade que hoje se apresenta (RAUD, 1999).

O Estado Santa Catarina tem passado por processos de mudança e desenvolvimento; desde a Constituição Brasileira da década de 1980, vem implementando ações voltadas ao incentivo da descentralização e à aproximação da população na gestão dos territórios (RAUD, 1999). Porém é um processo lento e que não ocorre em um fluxo de planejamento contínuo: a cada quatro anos, alterações são realizadas conforme a administração estadual que assume.

O Território Oeste Catarinense é composto por vinte e cinco municípios situados entre os territórios Meio Oeste Contestado e Extremo Oeste; os três, em conjunto, constituem a região da Grande Fronteira do MERCOSUL. O TOC possui uma população de 324.594 habitantes e uma densidade demográfica de 75,7 habitantes por Km² (PTDRS, 2010).

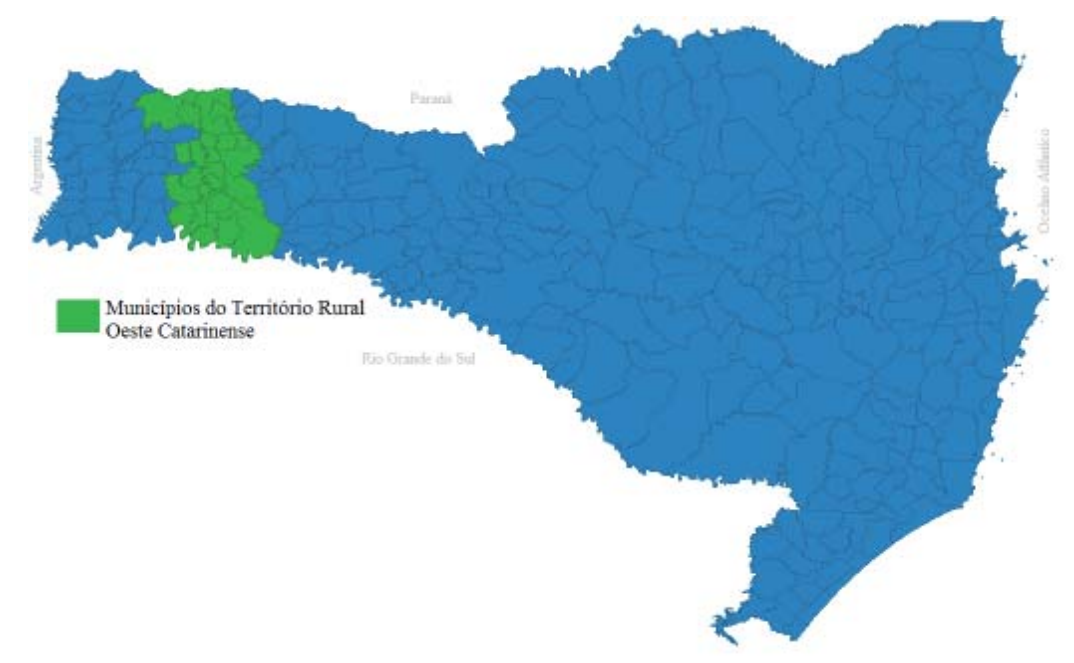

Figura 1 - Mapa de localização do Território Oeste Catarinense Fonte: Elaboração própria (2016).

A história do Território Oeste Catarinense caracteriza-se pela exclusão de indígenas Kaingangs, Xoklengs, Guaranis e dos caboclos que ali habitavam. A política desenvolvimentista se deu no século XX; buscava o fortalecimento dos interesses da produção, com incentivo dos governos federal e estadual, sem muito se preocupar com a cultura, a população existente. As empresas chamadas "colonizadoras" dividiam as terras em lotes para serem vendidos às famílias de descendentes europeus (PTDRS, 2010).

Os imigrantes se apossavam das terras e iniciavam sua produção, não observando o que ali havia. Esse processo desigual causou diversos impactos sociais e ambientais, tornando as comunidades homogêneas. Esse território, ao longo dos anos, acumulou problemas como o êxodo rural, a concentração de terras nas mãos de poucos e impactos ambientais que, até os dias atuais, não foram solucionados (RENK, 2004).

De 1940 a 1960, o processo de colonização foi-se consolidando e determinando as características do TOC, sendo que, na década de 1970, o processo de agroindustrialização foi implantado, destacando-se no setor das carnes (PTDRS, 2010).

A identidade do Território Oeste Catarinense ligada à valorização dos saberes locais e ao desenvolvimento endógeno ainda é um processo em construção, que também vem sendo promovido com o surgimento dos Empreendimentos de Economia Solidária. 


\section{ANÁLISE E DISCUSSÃO DOS DADOS}

O Território Oeste Catarinense possui uma população rural expressiva em quase todos os seus vinte e cinco municípios. Conforme apresenta a tabela 1, em 14 municípios, a população rural representa mais de 50\% do total da população. Em apenas 2 municípios, Chapecó e Pinhalzinho, a porcentagem da população rural ficou abaixo de 20\%, o que se justifica por Chapecó ser uma cidade polo, com diversas indústrias e comércio diverso, favorecendo o crescimento da população urbana; da mesma forma, Pinhalzinho, que possui elevado número de empresas atuantes, com capacidade para gerar empregos e atrair a população à área urbana.

Tabela 1 - Evolução populacional, populações rural e urbana

\begin{tabular}{lcccc}
\hline Município & $\begin{array}{c}\text { População em } \\
2010\end{array}$ & Urbana & Rural & $\begin{array}{c}\text { \% que representava o rural } \\
\text { em 2010 }\end{array}$ \\
\hline Águas de Chapecó & 6.109 & 3.236 & 2.873 & $47 \%$ \\
Águas Frias & 2.424 & 981 & 1.443 & $60 \%$ \\
Campo Erê & 9370 & 6.252 & 3.118 & $33 \%$ \\
Caxambu do Sul & 4.406 & 2.150 & 2.256 & $51 \%$ \\
Chapecó & 183.561 & 168.159 & 15.402 & $8 \%$ \\
Cordilheira Alta & 3.767 & 1.468 & 2.319 & $61 \%$ \\
Coronel Freitas & 10.213 & 6.067 & 4.146 & $41 \%$ \\
Formosa do Sul & 2.601 & 1.084 & 1.517 & $58 \%$ \\
Guatambu & 4.675 & 1.749 & 2.926 & $63 \%$ \\
Irati & 2.096 & 449 & 1.647 & $79 \%$ \\
Jardinópolis & 1.766 & 799 & 967 & $55 \%$ \\
Nova Erechim & 4.275 & 3.211 & 1.064 & $25 \%$ \\
Nova Itaberaba & 4.267 & 1.530 & 2.737 & $64 \%$ \\
Novo Horizonte & 2.750 & 921 & 1.829 & $67 \%$ \\
Pinhalzinho & 16.335 & 13.618 & 2.717 & $17 \%$ \\
Planalto Alegre & 2.679 & 1.066 & 1.593 & $60 \%$ \\
Quilombo & 10.284 & 5.749 & 4.502 & $44 \%$ \\
Santiago do Sul & 1.465 & 650 & 815 & $56 \%$ \\
São Bernardino & 2.677 & 719 & 1.960 & $73 \%$ \\
São Carlos & 10.284 & 6.899 & 3.385 & $33 \%$ \\
São Lourenço do Oeste & 21.797 & 16.885 & 4.912 & $23 \%$ \\
Saudades & 9.016 & 5.123 & 3.893 & $43 \%$ \\
Serra Alta & 3.285 & 1.835 & 1.450 & $44 \%$ \\
Sul Brasil & 2.766 & 1.011 & 1.755 & $63 \%$ \\
União do Oeste & 2.910 & 1.107 & 1.803 & $62 \%$ \\
\hline Fonte: Elaboraca prob & & & \\
\hline
\end{tabular}

Fonte: Elaboração própria, com base em dados do IBGE (2010).

Com o objetivo de apresentar os principais dados dos Empreendimentos de Economia Solidária (EES) existentes no Território Oeste Catarinense (TOC), utilizou-se o mapeamento existente no SIES. No primeiro mapeamento, publicado no ano de 2007, foram identificados 100 empreendimentos que se declararam como de Economia Solidária no território em estudo. No segundo mapeamento, publicado no ano de 2014, foram declarados 90, ou seja, ocorreu uma redução dos EES existentes no TOC, conforme indica a tabela 2. 
Tabela 2 - Mapeamento dos EES no Território Oeste Catarinense, em 2007 e 2014

\begin{tabular}{lcc}
\hline Município & Número de EES - 2007 & Número de EES - 2014 \\
\hline Águas de Chapecó & 0 & 2 \\
Águas Frias & 1 & 2 \\
Campo Erê & 3 & 1 \\
Caxambu do Sul & 6 & 4 \\
Chapecó & 45 & 35 \\
Cordilheira Alta & 1 & 2 \\
Coronel Freitas & 4 & 3 \\
Formosa do Sul & 3 & 4 \\
Guatambu & 11 & 9 \\
Irati & 2 & 2 \\
Jardinópolis & 0 & 0 \\
Nova Erechim & 2 & 1 \\
Nova Itaberaba & 1 & 1 \\
Novo Horizonte & 0 & 5 \\
Pinhalzinho & 4 & 7 \\
Planalto Alegre & 0 & 1 \\
Quilombo & 10 & 5 \\
Santiago do Sul & 3 & 3 \\
São Bernardino & 0 & 0 \\
São Carlos & 0 & 1 \\
São Lourenço do Oeste & 1 & 0 \\
Saudades & 2 & 1 \\
Serra Alta & 0 & 0 \\
Sul Brasil & 1 & 0 \\
União do Oeste & 0 & 1 \\
\hline TOTAL & 100 & 90 \\
\hline Font Elaboca & propra &
\end{tabular}

Fonte: Elaboração própria, com base no Banco de Dados do ATLAS (2014).

Destaca-se que ocorreu redução de EES em nove municípios, e aumento deles em 16. 0 município de Chapecó apresentou uma redução de 10 empreendimentos, enquanto Quilombo teve redução de cinco EES.

Os empreendimentos constituem a célula base da Economia Solidária; embora sua organização vise à inserção econômica, as dimensões políticas, sociais, ambientais estão sempre presentes, traduzindo-se, principalmente, em questões relativas à tomada de decisões quando ao território onde estão inseridos.

De acordo com Motta (2007), a Economia Solidária é condição necessária para enfrentar os diversos problemas que cercam os agricultores familiares. A integração da Economia Solidária e da Agricultura Familiar pode ser considerada uma alternativa de desenvolvimento para o País, um desenvolvimento sustentável.

No caso dos EES do Território Oeste Catarinense, os grupos iniciam como informais e, após algum tempo, consolidam suas organizações em associações e/ou cooperativas. Diversos empreendimentos também permanecem um período como associação e posteriormente passam a ser cooperativa, atraídos principalmente pelo acesso ao crédito que as cooperativas possuem. 
O quadro 1 indica que 24\% dos EES possuem área de atuação essencialmente urbana; quanto aos demais, 50\% atuam nas áreas rurais, e 26\% desenvolvem atividades tanto na área rural quanto na urbana.

\begin{tabular}{|c|c|c|}
\hline Características dos EES & Ano & Território Oeste Catarinense \\
\hline Área de atuação & 2014 & $\begin{array}{l}\text { Rural: } 50 \% \\
\text { Urbana: } 24 \% \\
\text { Rural e Urbana: } 26 \% \\
\end{array}$ \\
\hline Forma de organização & 2014 & $\begin{array}{l}\text { Grupo informal: } 17 \% \\
\text { Associação: } 43 \% \\
\text { Cooperativa: } 39 \% \\
\text { Sociedade mercantil: } 1 \% \\
\end{array}$ \\
\hline Motivação para iniciar & 2014 & $\begin{array}{l}\text { Uma alternativa ao desemprego: } 17 \% \\
\text { Obter maiores ganhos em um empreendimento associativo: } 33 \% \\
\text { Uma fonte complementar de renda para os associados: } 23 \% \\
\text { Desenvolver uma atividade em que todos são donos: } 1 \% \\
\text { Condição exigida para ter acesso a financiamentos e outros apoios: } \\
4 \% \\
\text { Motivação social, filantrópica e religiosa: } 4 \% \\
\text { Desenvolvimento comunitário de capacidades e potencialidades: } 1 \% \\
\text { Alternativa organizativa e de qualificação: } 9 \% \\
\text { Outros (não citam motivos): } 8 \%\end{array}$ \\
\hline $\begin{array}{l}\text { Para quem é feita a } \\
\text { comercialização }\end{array}$ & 2014 & $\begin{array}{l}\text { Venda direta ao consumidor final: } 59 \% \\
\text { Venda a revendedores e atacadistas: } 22 \% \\
\text { Venda a órgão governamental: } 13 \% \\
\text { Venda para empresas privadas de produção: } 8 \% \\
\text { Venda ou troca com outros EES: } 5 \%\end{array}$ \\
\hline Número de homens & 2014 & 2.228 \\
\hline Número de mulheres & 2014 & 1.306 \\
\hline Categoria social & 2014 & $\begin{array}{l}\text { Agricultores familiares: } 64 \% \\
\text { Artesãos: } 11 \% \\
\text { Artistas: } 0 \% \\
\text { Assentados da reforma agrária: } 0 \% \\
\text { Catadores de material reciclável: } 2 \% \\
\text { Garimpeiros e mineiros: } 0 \% \\
\text { Técnicos profissionais de nível superior: } 0 \% \\
\text { Trabalhadores autônomos/ por conta própria: } 5 \% \\
\text { Desempregados/ desocupados: } 7 \% \\
\text { Não se aplica ou não há predominância: } 11 \%\end{array}$ \\
\hline
\end{tabular}

Quadro 1 - Características dos EES - 2014

Fonte: elaboração própria, com base no Banco de Dados do ATLAS (2014).

A porcentagem de grupos informais é significativa, 17\%, o que nos leva a crer que são grupos iniciantes em suas atividades como Economia Solidária, e, até o momento, não definiram qual será a melhor opção de formalização. Prevalecem, no território, as organizações em forma de associação, 43\%; e, em forma de cooperativa, 39\%. No TOC, não há registros de empreendimentos que surgiram oriundos da recuperação de empresas falidas.

As atuais formas jurídicas pelas quais os Empreendimentos de Economia Solidária e as empresas de autogestão se organizam estão previstas no Código Civil, Lei 10.406, de 10 de janeiro 
de 2002, e em leis especiais. As associações são reguladas pelos artigos de 53 a 61 e de 44 a 52 da Lei 10.406, de 10 de janeiro de 2002 (Código Civil Brasileiro). As sociedades cooperativas são reguladas pelos artigos de 1.093 a 1.096 da lei 10.406, de 10 de janeiro de 2002, Código Civil Brasileiro; e pela legislação especial Lei 5.764/71 (BRASIL, 2012).

Quanto às motivações para a constituição dos EES, os dados indicam como principais fatores a obtenção de maiores ganhos em um empreendimento associativo, a perspectiva de uma fonte complementar de renda para os associados e de uma alternativa ao desemprego.

Ao serem questionados sobre se tiveram acesso a algum tipo de apoio, assessoria ou capacitação, os responsáveis por EES citaram que tiveram acesso a dois ou mais apoios, assessorias ou capacitações. "Essas assessorias são conseguidas de modo geral por meio de programas de apoio e por parcerias firmadas com entidades de origem e natureza institucional bem diversa" (SILVA, CARNEIRO, 2017, p. 79).

Esses EES utilizam, como principal estratégia de comercialização, a venda direta ao consumidor final, sendo que a venda a revendedores e atacadistas também possui um percentual significativo, bem como a venda a órgão governamental. No primeiro mapeamento do SIES, a venda para órgão governamental não acontecia; entende-se que, a partir da criação da SENAES e da abertura de editais públicos para a Economia Solidária, é que as instituições públicas também passaram a adquirir produtos oriundos dos empreendimentos.

Quanto à questão de gênero, no estudo em questão, a maior parte dos sócios são homens, 2.228; enquanto as mulheres são 1.306 sócias. O município de Coronel Freitas não possui nenhuma mulher cadastrada; o de Campo Erê, somente duas. Essa realidade do TOC é semelhante aos dados do Brasil, esfera em que 61\% dos envolvidos são homens, e 39\% mulheres; esse predomínio masculino no País está ligado a empreendimentos que desenvolvem atividades como agricultura, pecuária e reciclagem. Um fator que pode ser motivo da existência de um número menor de mulheres nos EES do Território Oeste Catarinense é o de que elas cuidam da organização, produção, confecção, enquanto os homens são os que fazem a comercialização, sendo somente eles a se registrar nos empreendimentos.

Em relação à categoria social da totalidade dos sócios, nota-se que os empreendimentos existentes no território são, em sua maioria, $64 \%$, de agricultores familiares; em seguida, $11 \%$ de artesãos, $7 \%$ de desempregados, 5\% de trabalhadores autônomos e 11\% que identificaram não se aplicar nenhuma das opções contidas no questionário.

No que tange a investimentos realizados nos últimos 12 meses, 50\% dos EES responderam que os realizaram, e $50 \%$ que não realizaram investimentos. E $75 \%$ dos EES não buscaram nos últimos 12 meses acessar linha de crédito ou financiamento, enquanto $25 \%$ o fizeram.

Os EES citam como um dos seus principais desafios a manutenção econômica; buscam encontrar formas de viabilizar economicamente a continuidade do trabalho, bem como gerar a renda adequada para os participantes. Também apontam como desafios a participação dos associados, a efetivação da autogestão, o alcance da conscientização e politização para manter a união do coletivo. Outro desafio concerne à promoção e articulação com outros empreendimentos e com o Movimento de Economia Solidária.

Percebe-se que a realidade dos EES no Território Oeste Catarinense apresenta peculiaridades que são próprias da região. Então, torna-se importante perceber e compreender tais características para a formulação de políticas públicas que auxiliem e promovam o desenvolvimento territorial. 


\section{CONSIDERAÇÕES FINAIS}

O objetivo principal deste estudo foi apresentar os principais dados dos Empreendimentos de Economia Solidária (EES) existentes no Território Oeste Catarinense (TOC). Com base nas análises realizadas, constatou-se que a categoria social mais presente nos empreendimentos solidários é a de agricultores familiares.

Em relação às questões de gênero, os empreendimentos são compostos, em sua maior parte, por homens, o que sugere a necessidade de um estudo mais aprofundado, uma vez que, pertencendo os EES à agricultura familiar, o número de mulheres e homens deveria manter maior equilíbrio.

No que se refere aos investimentos realizados, 50\% dos EES realizaram investimentos nos últimos 12 meses, e 50\% não o fizeram. Os investimentos realizados foram, em sua maioria, oriundos de recursos próprios, uma vez que $75 \%$ dos respondentes informaram que não buscaram acessar, no mesmo período, nenhuma linha de crédito ou financiamento.

Em relação à motivação para que os EES se iniciassem, percebe-se que a Economia Solidária é visualizada como uma oportunidade de geração de renda, através da produção e da comercialização dos produtos. Entende-se que a Economia Solidária possibilita o avanço no desenvolvimento territorial sustentável. Além disso, possibilita a busca por espaços de autogestão, trabalho justo, valorização humana, comércio justo, consumo consciente, participação e solidariedade.

Pressupõe-se que os mesmos fatores apontados como motivações para iniciar os EES apresentam-se como os principais desafios para sua continuidade: a busca por formas de viabilização econômica dos EES e a geração de uma renda adequada aos sócios e sócias.

Destaca-se que a solidariedade, a autogestão e a realização do trabalho mais autônomo, como "dono do negócio", estiveram presentes em boa parte das respostas dos EES do Território Oeste Catarinense, levando ao entendimento de que o processo democrático que ocorre possibilita a participação de todos e o aumento da produção e da comercialização. Os EES atuantes no Território Oeste Catarinense apresentam-se como atores que contribuem para o desenvolvimento e fortalecem as relações humanas.

Este estudo é relevante pois aborda aspectos que impactam diretamente na vida de muitas pessoas do TOC. Mediante os apontamentos, é possível identificar que conhecer os dados sobre os EES é o primeiro passo para que gestores públicos e entidades de apoio possam contribuir para a formação de empreendimentos autônomos, fortalecidos e inseridos nas políticas públicas e sociais.

Como limitação, aponta-se que a análise foi realizada com base em dados secundários. Como sugestão para pesquisas futuras, indica-se a realização de estudos com pesquisa de campo e posterior comparação com este e outros estudos sobre o tema.

\section{REFERÊNCIAS}

ATLAS. Atlas Digital da Economia Solidária. 2014. Disponível em: <atlas.sies.org.br>. Acesso em: out. 2016. AMARAL FILHO. Jair. A endogeneização no desenvolvimento econômico regional e local. Planejamento e Políticas Públicas, n. 23, p. 261-86, jun. 2001.

BENINI, Édi A.; FARIA, Maurício Sardá de; NOVAES, Henrique T.; DAGNINI, Renato. Gestão pública e sociedade: fundamentos e políticas públicas de Economia Solidária. São Paulo: Outras Expressões, 2012.

BRASIL. Avanços e desafios para as políticas públicas de Economia Solidária no Governo Federal 2003/2010. Brasília: [s.n.], 2012. 
Atlas da Economia Solidária no Brasil 2005-2007. Organização da Associação Nacional dos Trabalhadores e Empresas de Autogestão e Participação Acionária - ANTEAG. São Paulo: Todos os Bichos, 2009.

CACCIA BAVA, Silvio. Trocando a riqueza de mãos: distribuição de renda e poder nas pequenas cidades. Revista Proposta, Rio de Janeiro, n. 54, p. 12-6, ago. 1994.

COELHO, Franklin Dias. Reestruturação econômica, políticas públicas e as novas estratégias de desenvolvimento local. São Paulo: Publicações Polis, 1997.

ESTEVA, Gustavo. Desenvolvimento. In: SACHS, Wolfgang (Ed.). Dicionário do desenvolvimento: guia para o conhecimento como poder. Petrópolis, RJ: Vozes, 2000.

FAVARIN, Roque Ademir. A construção de políticas públicas de economia solidária: estado e sociedade civil devem se completar? 2010. Disponível em: <http://www.apec.unesc.net>. Acesso em: 15 dez. 2016. FÓRUM BRASILEIRO DE ECONOMIA SOLIDÁRIA (FBES). Parabéns aos 10 anos do Fórum Brasileiro de Economia Solidária. 2013. Disponível em: <http://fbes.org.br>. Acesso em: 10 abr. 2016.

GIL, A. Carlos. Como elaborar projetos de pesquisa. São Paulo: Atlas, 2002.

INSTITUTO BRASILEIRO DE GEOGRAFIA E ESTATíSTICA (IBGE). Censo Demográfico. 2010. Disponível em: <http://www.censo2010.ibge.gov.br/sinopse/>. Acesso em: 10 ago. 2016.

INSTITUTO DE PESQUISA ECONÔMICA APPLICADA (IPEA). Atlas do Desenvolvimento Humano no Brasil. 2013. Disponível em: <http://www.atlasbrasil.org.br/2013/pt/consulta/>. Acesso em: 10 ago. 2016.

LEITE, Sergio Pereira; WESZ JUNIOR, Valdemar João. Um estudo sobre o financiamento da política de desenvolvimento territorial no meio rural brasileiro. Revista de Economia e Sociologia Rural, Brasília, v. 50, n. 4, out./dez. 2012.

MORAES, Jorge Luiz Amaral de. Capital social e políticas públicas para o desenvolvimento regional sustentável. Revista Centro de Ciências Administrativas, Fortaleza, v. 9, n. 2, p. 196-204, dez. 2003.

MOTTA, Eugênia de Souza Guimarães. Economia Solidária e agricultura familiar, uma integração necessária. Revista Democracia Viva, Rio de Janeiro, n. 35, p. 80-4, jun. 2007.

PLANO TERRITORIAL DE DESENVOLVIMENTO RURAL SUSTENTÁVEL (PTDRS). Oeste Catarinense. 2010. Disponível em: <http://sit.mda.gov.br/download/ptdrs/ptdrs_qua_territorio066.pdf>. Acesso em: 15 jan. 2016.

RAUD, Cecile. Indústria, território e meio ambiente no Brasil. Florianópolis: UFSC; Blumenau: FURB, 1999. RENK, Arlene. Narrativas da diferença. Chapecó, SC: Argos, 2004.

SILVA, Sandro Pereiro; CARNEIRO, Leandro Marcondes. Os novos dados do mapeamento de economia solidária no Brasil: apontamentos iniciais para o debate. Brasília: IPEA, 2014.

SINGER, Paul. Economia Solidária. In: CATTANI, Antônio David (Org.). A outra Economia. Porto Alegre: Veraz, 2003.

TRIVIÑOS, Augusto N. S. Introdução à pesquisa em ciências sociais. São Paulo: Atlas, 2009.

\section{Sobre os autores:}

Andreia Casagrande: Mestre em Políticas Sociais e Dinâmicas Regionais. Docente da Faculdade Senac Chapecó. E-mail: andreiabegnini@gmail.com

Sérgio Begnini: Doutorando em Administração - Universidade do Oeste de Santa Catarina (UNOESC). E-mail: sergiobegnini@gmail.com 